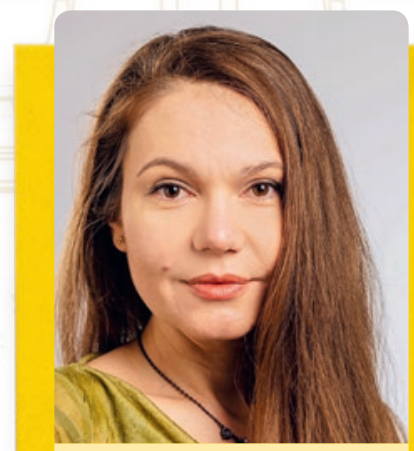

Dr. med. Dana Pamfile (c CHUV)

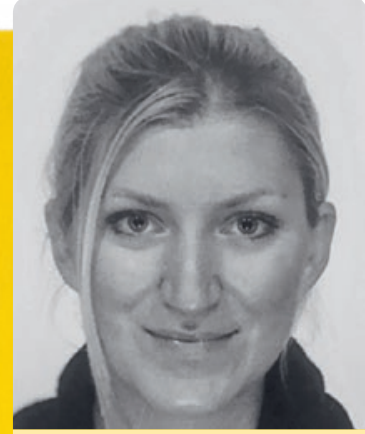

Dr. med. Eva Schindowski (c zVg)

\title{
Beste Facharztprüfungen
}

\section{Teil 2020 - Psychiatrie und Psychotherapie}

Die Schweizerische Gesellschaft für Psychiatrie und Psychotherapie (SGPP) hat die besten Facharztprüfungen 2. Teil 2020 gekürt.

1. Preis: Dr. med. Selma Baldursson, «Über die Bedeutung der therapeutischen Beziehung im Rahmen einer psychodynamischen Psychotherapie am Fallbeispiel einer strukturell gestörten Patientin», Luzern

2. Preis: Dr. Dana Pamfile, «Le devenir adulte en crise Un regard psychodynamique sur les fragilités identitaires du jeune adulte», Lausanne

3. Preis: Dr. med. Eva Maria Schindowski, «Chronisch therapieresistente Depression bei Religiosität mit negativem religiösem Coping», Zürich

\section{Deutsche Menopause Gesellschaft} e.V. - «Neues aus der Wissenschaft»

Cand. med. Livia Nakhostin der Universität Bern gewinnt mit ihrer Dissertation den Wissenschaftspreis der Deutschen Menopause Gesellschaft. Ihre Arbeit widmet sich der Frage, wie Hormonersatztherapien während der Menopause das Risiko beeinflussen, an Darmkrebs zu erkranken.

Die Dissertation absolvierte sie unter der Leitung von Prof. Dr. med. Stute an der Frauenklinik in Bern.

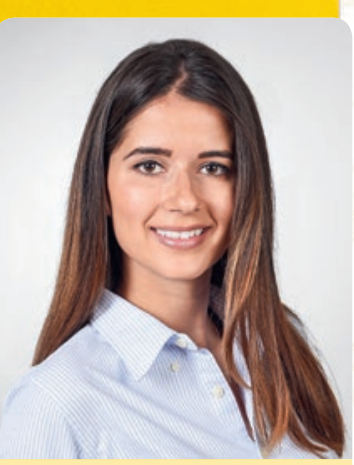

Cand. med. Livia Nakhostin (๔ $\mathrm{zVg}$ )

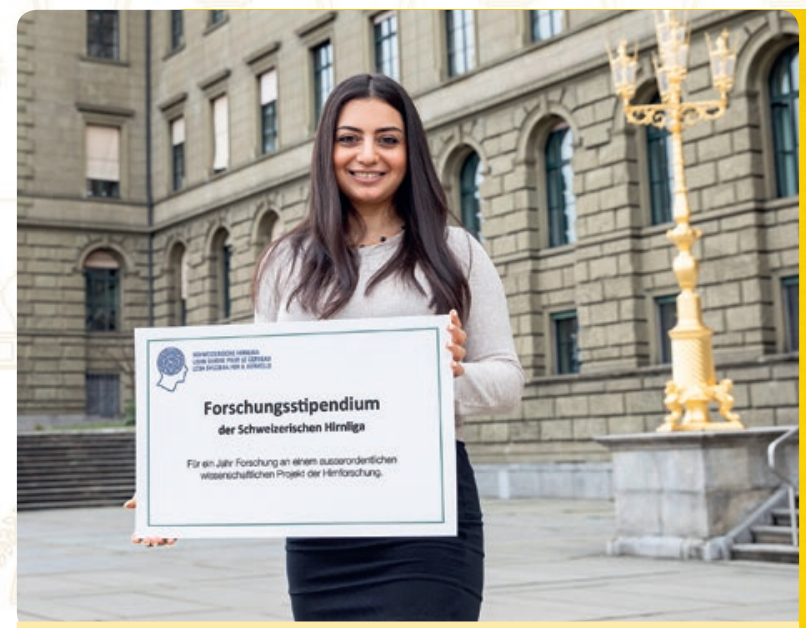

Forschungsstipendium der Schweizerischen Hirnliga 2021

Das Forschungsstipendium 2021 der Schweizerischen Hirnliga geht an Mahshid Gazorpak, PhD-Kandidatin in Molekular- und Verhaltensneurowissenschaften an der ETH Zürich.

Sie erforscht, wie Stress-Rezeptor-Proteine die Stressreaktion im Gehirn beeinflussen.

Das Forschungsstipendium ist mit CHF 60000 dotiert und fördert Gazorpaks wissenschaftliche Arbeit während eines Jahres.

M.Sc. Mahshid Gazorpak, PhD-Kandidatin (๔ zVg) 